\title{
PENGARUH KEPUASAN KERJA, KOMITMEN ORGANISASIONAL DAN MOTIVASI KERJA TERHADAP ORGANIZATIONAL CITIZENSHIP BEHAVIOR
}

\author{
I Putu Adi Kususma Putra ${ }^{1}$ \\ I Gede Adnyana Sudibya ${ }^{2}$ \\ ${ }^{1,2}$ Fakultas Ekonomi dan Bisnis Universitas Udayana (Unud), Bali, Indonesia \\ e-mail: adikusuma6996@gmail.com
}

\begin{abstract}
ABSTRAK
Tujuan penelitian ini adalah untuk mengetahui pengaruh kepuasan kerja, komitmen organisasi, dan motivasi kerja perilaku kewargaan organisasi di LPD Tanjung Benoa. Populasi dalam penelitian ini adalah seluruh karyawan di LPD Tanjung Benoa yang berjumlah 32 orang. Sampel yang digunakan dalam penelitian ini adalah seluruh populasi 32 orang dengan partisipasi pemimpin. Dengan metode penentuan sampling jenuh adalah teknik penentuan sampel ketika semua anggota populasi digunakan sebagai sampel. Penelitian ini menggunakan analisis regresi linier berganda untuk menguji pengaruh kepuasan kerja, komitmen organisasi dan motivasi kerja terhadap OCB di LPD Tanjung Benoa. Hasil penelitian menunjukkan bahwa kepuasan kerja, komitmen organisasi dan motivasi kerja berpengaruh positif dan signifikan terhadap karyawan OCB di LPD Tanjung Benoa. Artinya, semakin tinggi kepuasan kerja, komitmen organisasi dan motivasi kerja yang dimiliki oleh karyawan, maka akan meningkatkan karyawan OCB LPD Tanjung Benoa.
\end{abstract}

Kata kunci: kepuasan kerja, komitmen organisasional, motivasi kerja, perilaku kewargaan organisasional

\begin{abstract}
The purpose of this study is to determine the effect of job satisfaction, organizational commitment, and work motivation of organizational citizenship behavior in LPD Tanjung Benoa. The population in this research is all employees in LPD Tanjung Benoa which amounted to 32 people. The sample used in this study is the entire population of 32 people with the participation of leaders. By the method of determining saturated sampling is the technique of determining the sample when all members of the population used as a sample. This research uses multiple linear regression analysis to test the effect of job satisfaction, organizational commitment and work motivation to OCB in LPD Tanjung Benoa. The results showed that job satisfaction, organizational commitment and work motivation had a positive and significant effect on OCB employees in LPD Tanjung Benoa. That is, the higher job satisfaction, organizational commitment and work motivation owned by employees, it will increase the OCB LPD employees Tanjung Benoa.
\end{abstract}

Keywords: job satisfaction, organizational commitment, work motivation, organizational citizenship behavior 
I Putu Adi Kusuma Putra, Pengaruh Kepuasan Kerja, Komitmen Organisasional...

\section{PENDAHULUAN}

Sumber daya manusia merupakan sumber daya yang digunakan untuk mensinergikan sumber daya lainnya untuk mencapai tujuan organisasi. Tanpa adanya sumber daya manusia, aktivitas perusahaan tidak akan terjadi (Hasibuan, 2008:12). Pengelolaan sumber daya manusiadewasa ini merupakan suatu keharusan dan bukan lagi merupakan suatu pilihan apabila perusahaan ingin berkembang. Salah satu yang harus diperhatikan adalah rasa suka rela karyawan dalam membantu rekan kerja di luar tanggung jawab. Untuk dapat mengelola SDM dengan baik, setiap pemimpin dan manajer serta bagian yang menangani SDM harus mengerti masalah manajemen SDM dengan baik pula (Widodo, 2015). Menurut Ardana dkk. (2012:3) SDM adalah harta atau asset yang paling berharga dan paling penting dimiliki oleh suatu organisasi/perusahaan, karena keberhasilan organisasi sangat ditentukan oleh unsur manusia.

Keberhasilan suatu organisasi/perusahaan sangat dipengaruhi oleh kualitas SDM yang mengawalinya, SDM tersebut akan baik kualitasnya dan kinerjanya bila dipimpin dan dikelola dengan baik. Untuk dapat mengelola SDM dengan baik, setiap pemimpin dan manajer serta bagian yang menangani SDM harus mengerti masalah yang terjadi pada organisasi (Widodo, 2015). Dalam menjalankan sejumlah tugas dalam organisasi dan untuk dapat bersaing dengan kompetitor, SDM tidak cukup hanya melakukan tugasnya masing-masing sesuai dengan job description (deskripsi pekerjaan) saja, namun mereka harus memiliki perilaku extra-role (peran ekstra) yang dapat memberi pengaruh positif bagi produktivitas organisasi. 
Cholil dan Riani (2003) mengatakan bahwa karyawan adalah sebagai modal utama bagi perusahaan oleh sebab itu karyawan perlu dikelola agar tetap menjadi produktif akan tetapi dalam pengelolaannya bukanlah hal yang mudah, karena karyawan mempunyai pikiran, status, serta latar belakang yang berbeda. Perdana (2010) menjelaskan bahwa salah satu perilaku yang dapat meningkatkan produktivitas karyawan didalam organisasi yaitu perilaku extra-role (peran ekstra) atau disebut juga perilaku Organizational Citizenship Behavior (OCB). Peran ekstra karyawan ini tercermin melalui perilaku suka menolong orang lain, menjadi volunteer (suka relawan) untuk tugas-tugas ekstra, patuh terhadap aturan-aturan dan prosedur-prosedur di tempat kerja.

$O C B$ merupakan perilaku ekstra yang tidak menjadi bagian dari kewajiban kerja formal seorang pegawai, namun mendukung berfungsinya perusahaan secara efektif (Robbins, 2009:40). Organ et al. (2006) mendefinisikan $O C B$ sebagai perilaku individual yang bersifat bebas, yang tidak secara langsung dan eksplisit mendapat penghargaan dari sistem imbalan formal, dan yang secara keseluruhan (agregat) meningkatkan efisiensi dan efektifitas fungsi-fungsi perusahaan, bersifat bebas dan sukarela karena perilaku tersebut tidak diharuskan oleh persyaratan peran atau deskripsi jabatan yang secara jelas dituntut berdasarkan kontrak dengan perusahaan, melainkan sebagai pilihan personal.

$O C B$ dapat timbul dari berbagai faktor dalam organisasi, di antaranya karena adanya kepuasan kerja dari karyawan (Robbin \& Judge, 2007). Ketika karyawan merasakan kepuasan terhadap pekerjaan yang dilakukannya, maka karyawan tersebut akan bekerja secara maksimal dalam menyelesaikan 
I Putu Adi Kusuma Putra, Pengaruh Kepuasan Kerja, Komitmen Organisasional...

pekerjaannya, bahkan melakukan beberapa hal yang mungkin di luar tugasnya. Hariandja (2009:290) mendefinisikan kepuasan kerja adalah salah satu elemen yang cukup penting dalam organisasi yang dapat mempengaruhi perilaku kerja seperti malas, rajin, produktif, atau mempunyai hubungan beberapa jenis perilaku yang sangat penting dalam organisasi. Kepuasan kerja karyawan merupakan masalah penting yang perlu diperhatikan dalam hubungannya dengan produktivitas kerja karyawan (Sutrisno, 2014:77).

Krishnan et al. (2009) menunjukkan bahwa baik kepuasan kerja intrinsik maupun kepuasan kerja ekstrinsik berpengaruh signifikan terhadap OCB. kepuasan kerja berpengaruh positif signifikan terhadap OCB. Kepuasan yang dirasakan oleh karyawan yang berasal berasal dari gaji, promosi, supervisi, rekan kerja, ataupun pekerjaan yang dilakukannya akan meningkatkan OCB. Hal yang sangat penting dari indikator kepuasan kerja adalah pekerjaan itu sendiri. Ketika karyawan merasakan nyaman bekerja atau pekerjaannya mampu mengembangkan potensi yang dimilikinya, dalam arti memberikan tantangan, maka itu menjadi indicator kepuasan kerja yang baik (Darmawati dan Indartono, 2015).

Terdapat keyakinan bahwa karyawan yang puas akan lebih produktif dibandingkan dengan karyawan yang tidak puas, walaupun masih banyak bukti yang mempertanyakan hubungan sebab-akibat tersebut (Robbins, 2009:42). Oleh karena itu, kepuasan kerja merupakan salah satu faktor yang membentuk OCB, pernyataan tersebut sangat logis yang menganggap bahwa kepuasan kerja merupakan penentu utama OCB karyawan (Robbins, 2006). 
Selain kepuasan kerja, yang dapat mempengaruhi peran ekstra karyawan adalah komitmen organisasional karyawan. Komitmen memberikan pengaruh yang positif terhadap OCB. Hal ini dipengaruhi oleh indikasi bahwa karyawan yang memiliki loyalitas dan komitmen akan berusaha semaksimal mungkin untuk mencapai tujuan dan bertanggung jawab atas segala pekerjaan dan aktif mencari informasi - informasi penting yang berguna bagi organisasi. Selain itu karyawan telah memiliki keterikatan emosional sehingga dengan rela dan ikhlas melakukan perilaku ekstra seperti membantu rekan kerja lain yang membutuhkan tanpa mengharapkan imbalan. Namun komitmen diperoleh tidak signifikan disebabkan responden tidak didominasi oleh karyawan yang telah memiliki loyalitas dan komitmen yang tinggi, karena komitmen tidak dapat muncul dengan setahun atau dua tahun bekerja tetapi butuh proses dan waktu (Prameswari dan Suwandana, 2017). Fitria dkk. (2015) juga menemukan bahwa ada peranan yang bersifat positif antara komitmen organisasi dengan OCB pada perawat. Artinya semakin tinggi komitmen organisasi maka akan semakin tinggi OCB yang dilakukan.

Komitmen organisasional merupakan salah satu faktor penting yang berperan dalam membentuk peran ekstra karyawan. Komitmen organisasional merupakan sikap yang merefleksikan loyalitas karyawan pada perusahaan dan proses berkelanjutan dimana anggota organisasi mengekspresikan perhatiannya terhadap organisasi pada keberhasilan dan kemajuan yang berkelanjutan. Dimana komitmen normatif mempunyai hubungan yang lebih kuat dari pada komitmen afektif, sementara komitmen berkelanjutan mempunyai hubungan yang negatif terhadap kepatuhan. Wagner dan Rush (2000) menemukan komitmen 
I Putu Adi Kusuma Putra, Pengaruh Kepuasan Kerja, Komitmen Organisasional...

organisasional berpengaruh pada OCB. Ackfeldt dan Coote (2000) menyatakan bahwa komitmen organisasional berpengaruh pada OCB.

Faktor lain yang dapat membentuk OCB pada karyawan adalah motivasi kerja karyawan. Motivasi Kerja mempunyai pengaruh terhadap OCB yang positif. Hal tersebut membuktikan bahwa Motivasi Kerja yang baik, secara langsung dapat menghasilkan kinerja organisasi maupun kinerja individu secara optimal (Simon dan Naftalia, 2016). Ketika karyawan sudah memiliki motivasi kerja yang tinggi maka akan terciptanya OCB pada karyawan, dimana karyawan akan lebih giat dalam melakukan pekerjaannya, bahkan karyawan dapat melakukan pekerjaan diluar dari tugas yang diberikan organisasi. Motivasi kerja adalah kesedian atau dorongan dari dalam diri seseorang untuk melakukan aktivitas tertentu untuk mencapai tujuan perusahaan. Menurut Winardi (2008:2) motivasi kerja dapat dikaitkan sebagai kesedian untuk melaksanakan upaya tinggi untuk mencapai tujuan-tujuan perusahaan, yang dikondisikan oleh kemampuan upaya, untuk memenuhi kebutuhan individual tertentu.

Pentingnya motivasi kerja disampaikan oleh Handoko (2009:86), sebagai kekuatan pendorong yang dapat mewujudkan suatu perilaku guna mencapai tujuan dan kepuasan dirinya. Hariyanti dan Primawestri (2010), menyebutkan motivasi kerja merupakan suatu proses dimana kebutuhan-kebutuhan mendorong seseorang untuk melakukan serangkaian kegiatan yang mengarah ke tercapainya suatu tujuan tertentu. Motivasi kerja bertujuan untuk menambah semangat dan gairah dalam menyelesaikan pekerjaan, bertanggung jawab dan memiliki disiplin yang 
tinggi. Semakin besar perhatian perusahaan terhadap motivasi kerja, semakin besar pula keinginan karyawan untuk melaksanakan tugas.

Motivasi kerja sangat penting bagi karyawan, dengan pemberian motivasi kerja yang tepat diharapkan setiap karyawan dapat terdorong untuk meningkatkan kinerja kerjanya. Definisi ideal untuk motivasi kerja mengacu pada kemampuan untuk kenginan untuk mengadopsi tingkat yang lebih tinggi dari efek pribadi dibenarkan oleh pencapaian tujuan organisasi, tujuan yang mengarah pada kepuasan kebutuhan individu tertentu (Gomes et al., 2013). Hasil ini ditemukan pada data empiris hasil penelitian yang dilakukan oleh Novliadi (2007) bahwa karyawan yang puas dengan hasil atau lingkungan kerjanya tidak akan mempunyai keinginan keluar dari pekerjaan atau melakukan turnover (pergantian kerja). Keinginan karyawan keluar dari perusahaan atau yang sering disebut "Turnover" (pergantian kerja) ini bisa timbul karena lingkungan kerja perusahaan yang tidak sesuai dengan kebutuhan dan harapan karyawan.

Hal-hal tersebut membuktikan bahwa kepuasan kerja merupakan faktor penting dalam menekan turnover intention karyawan. Secara realita seseorang yang merasakan kepuasan akan merasa nyaman berada di lingkungannya sehingga merasa sulit untuk meninggalkan organisasi. Oleh karena itu, maka lingkungan kerja harus sesuai dengan kebutuhan dan harapan karyawan, dan akan membawa dampak yang baik pada komitmen organisasional karyawan serta perilaku atau sikap yang ditimbulkan karyawan. Berkaitan dengan perilaku atau sikap karyawan terhadap perusahaan maka akan menimbulkan perilaku extra atau OCB (Bangkit, 2010). 
I Putu Adi Kusuma Putra, Pengaruh Kepuasan Kerja, Komitmen Organisasional...

Penelitian ini berusaha memperluas pemahaman mengenai peran ekstra karyawan di LPD Desa Pakraman Tanjung Benoa. LPD adalah lembaga keuangan yang memiliki peranan sebagai lembaga perkreditan yang efektif dan terarah untuk kesejahteraan desa serta untuk membantu masyarakat golongan ekonomi menengah. LPD Desa Pakraman Tanjung Benoa sebagai lembaga pembantu masyarakat yang berada di Desa Pakraman Tanjung Benoa, baik dari golongan kelas menengah kebawah sampai dengan golongan menengah keatas, sehingga masyarakat memperoleh kesejahteraan. LPD Desa Pakraman Tanjung Benoa sangat memerlukan karyawan yang memiliki peran ekstra di luar pekerjaannya untuk dapat mengoptimalkan kinerja karyawan pada organisasi.

Berdasarkan hasil dari pra-riset (pengamatan awal) terhadap 10 orang responden dari total sampel 32 orang karyawan di LPD Desa Pakraman Tanjung Benoa yang telah dilakukan kepada kepala LPD, badan pengawas internal, sekretaris, bendahara, kabag tabungan, kabag deposito, kabag kredit, bagian umum, dan kabag keamanan, maka ditemukan indikasi adanya ketidakpuasan kerja dan kurangnya peran ekstra yang dilakukan karyawan LPD Desa Pakraman Tanjung Benoa. Hal ini dapat ditinjau dari sikap karyawan di LPD Desa Pakraman Tanjung Benoa yang merasa pekerjaannya cenderung membosankan dan karyawan saat jam istrahat sudah selesai masih berada di kantin, sehingga karyawan jarang untuk melaksanakan tugas diluar dari job description (uraian tugas) yang diberikan oleh organisasi. Karyawan di LPD Desa Pakraman Tanjung Benoa lebih bersikap pasif pada organisasi dan hanya mementingkan dirinya sendiri, sehingga komitmen yang dimiliki oleh karyawan kepada organisasi 
menurun yang menyebabkan kecilnya kemungkinan karyawan melakukan pekerjaan diluar waktu jam kerjanya. Permasalahan selanjutnya mengenai motivasi kerja, dimana rendahnya semangat karyawan dalam bekerja karena hubungan yang terjalin antara karyawan dengan pimpinan maupun karyawan dengan rekan kerjanya tidak sesuai dengan harpan karyawan, sehingga kurangnya keinginan karyawan untuk membantu rekan kerjanya melainkan mementingkan pekerjaannya sendiri. Dari permasalahan yang telah dipaparkan maka dapat mengindikasi bahwa OCB karyawan di LPD Desa Pakraman Tanjung Benoa masih rendah. Berdasarkan uraian yang sudah dijelaskan, maka penelitian ini bertujuan untuk menjelaskan pengaruh kepuasan kerja, komitmen organisasional dan motivasi kerja terhadap OCB di LPD Desa Pakraman Tanjung Benoa.

Menurut Krishnan et al. (2009) menunjukkan bahwa baik kepuasan kerja intrinsik maupun kepuasan kerja ekstrinsik berpengaruh signifikan terhadap OCB. Triwibowo dan Arsanti (2016) menemukan bahwa kepuasan kerja memiliki hubungan yang signifikan dan positif terhadap OCB. Semakin karyawan puas dalam bekerja maka akan meningkatkan komitmen organisasi. Ngadiman et al. (2013) menyatakan kepuasan kerja mempunyai pengaruh yang signifikan terhadap OCB. Ini berarti bahwa lebih tinggi kepuasan kerja yang mereka peroleh maka lebih tinggi OCB dalam pribadi pengajarannya. Sedangkan penelitian yang dilakukan Darmawati dan Indartono (2015) menemukan bahwa kepuasan kerja berpengaruh positif signifikan terhadap OCB.

Kepuasan yang dirasakan oleh karyawan yang berasal berasal dari gaji, promosi, supervisi, rekan kerja, ataupun pekerjaan yang dilakukannya akan 
I Putu Adi Kusuma Putra, Pengaruh Kepuasan Kerja, Komitmen Organisasional...

meningkatkan OCB. Hal yang sangat penting dari indicator kepuasan kerja adalah pekerjaan itu sendiri. Ketika karyawan merasakan nyaman bekerja atau pekerjaannya mampu mengembangkan potensi yang dimilikinya, dalam arti memberikan tantangan, maka itu menjadi indikator kepuasan kerja yang baik.Selanjutnya, Dewi dan Suwandana (2016) menemukan adanya hubungan positif antara kepuasan kerja dan OCB. Jika semakin tinggi tingkat kepuasan kerja yang dirasakan oleh karyawan seperti beban kerja, gaji, promosi, pengawasan serta hubungan dengan rekan kerja maka OCB akan meningkat. Osman et al. (2015) menemukan kepuasan kerja memiliki hubungan positif dengan OCB.

$\mathrm{H}_{1}$ : Kepuasan kerja berpengaruh positif dan signifikan terhadap OCB.

Hasil penelitian sebelumnya olehMerry (2013) yang menyatakan bahwa komitmen organisasional mempunyai pengaruh positif dan signifikan terhadap OCB karyawan Rumah Sakit Bhayangkara trijata Denpasar. Zeinabadi (2010) menemukan bahwa komitmen organisasional mempunyai pengaruh yang signifikan terhadap OCB. Darmawati et al. (2013) menemukan bahwa komitmen organisasional memiliki hubungan yang signifikan terhadap OCB. Sedangkan Prameswari dan Suwandana (2017) menemukan bahwa komitmen memberikan pengaruh yang positif terhadap OCB. Hal ini dipengaruhi oleh indikasi bahwa karyawan yang memiliki loyalitas dan komitmen akan berusaha semaksimal mungkin untuk mencapai tujuan dan bertanggung jawab atas segala pekerjaan dan aktif mencari informasi - informasi penting yang berguna bagi organisasi. Selain itu karyawan telah memiliki keterikatan emosional sehingga dengan rela dan ikhlas melakukan perilaku ekstra seperti membantu rekan kerja lain yang 
membutuhkan tanpa mengharapkan imbalan. Namun komitmen diperoleh tidak signifikan disebabkan responden tidak didominasi oleh karyawan yang telah memiliki loyalitas dan komitmen yang tinggi, karena komitmen tidak dapat muncul dengan setahun atau dua tahun bekerja tetapi butuh proses dan waktu. Selanjutnya, Fitria dkk. (2015) menemukan bahwa ada peranan yang bersifat positif antara komitmen organisasi dengan OCB pada perawat. Artinya semakin tinggi komitmen organisasi maka akan semakin tinggi OCB yang dilakukan. Penelitian serupa oleh Kurniawan (2015) juga menemukan hasil bahwa komitmen organisasional khususnya komitmen normative berpengaruh secara signifikan terhadap OCB.

$\mathrm{H}_{2}$ : Komitmen organisasional berpengaruh positif dan signifikan terhadap OCB.

Hasil penelitian sebelumnya oleh Kusuma (2014) menunjukan bahwa adanya pengaruh positif motivasi kerja terhadap organizational citizenship behavior pegawai. Hal ini mengindikasikan bahwa semakin tinggi motivasi kerja pegawai maka semakin tinggi organizational citizenship behavior pegawai tersebut. Dengan jawaban tertinggi yang terletak pada item pertanyaan selalu berusaha menyelesaikan pekerjaan dengan standar organisasi dan item pertanyaan selalu berusaha untuk tidak melakukan kesalahan dalam pekerjaan yang berada pada indikator tingkat kegigihan. Pegawai yang memiliki tingkat kegigihan yang tinggi, maka motivasi kerjanya juga tinggi dan akan memberikan usaha yang maksimal untuk tercapainya tujuan organisasi, dengan tercapainya tujuan organisasi maka perusahaan dapat mencapai kesuksesan. 
I Putu Adi Kusuma Putra, Pengaruh Kepuasan Kerja, Komitmen Organisasional...

Budiyanto dan Oetomo (2011) dalam penelitiannya mengenai The Effect of Job Motivation, Work Environment and Leadership on Organizational Citizenship Behavior, Job Satisfaction and Public Service Quality in Magetan, East Java, Indonesia (Pengaruh Motivasi Kerja, Lingkungan Kerja dan Kepemimpinan Terhadap OCB, Kepuasan Kerja dan Kualitas Pelayan Publik di Magetan, Jawa Timur, Indonesia) menemukan bahwa adanya pengaruh motivasi kerja terhadap OCB sebesar 28,4\%. Simon dan Naftalia (2016) memperoleh hasil bahwa Motivasi Kerja mempunyai pengaruh terhadap OCB yang positif. Hal tersebut membuktikan bahwa Motivasi Kerja yang baik, secara langsung dapat menghasilkan kinerja organisasi maupun kinerja individu secara optimal.

Djati (2011) juga mengatakan bahwa motivasi kerja berpengaruh terhadap OCB. Suhardi dan Syaifullah (2017) menunjukkan bahwa motivasi berpengaruh signifikan terhadap OCB. Artinya semakin baik motivasi yang dimiliki seorang pegawai, maka akan baik pula OCB yang dimiliki oleh pegawai tersebut. Motivasi merupakan elemen yang sangat penting bagi kemajuan pegawai karena dengan motivasi dapat berpengaruh pada psikologis karyawan sehingga berimbas pada OCB. Oleh karena itu dapat dikatakan bahwa semakin tinggi motivasi kerja yang diberikan oleh perusahaan kepada pegawai maka akan semakin tinggi pula OCB pegawai untuk menjadi bagian dari tugasnya di perusahaan. Penelitian serupa oleh Dewi (2015) menemukan hasil bahwa secara signifikan faktor Motivasi Prestasi dan Motivasi Afiliasi berpengaruh terhadap OCB pegawai.

$\mathrm{H}_{3}$ : Motivasi Kerja berpengaruh positif dan signifikan terhadap Organizational Citizenship Behavior. 


\section{METODE PENELITIAN}

Pendekatan yang akan digunakan untuk meneliti sumber masalah pada penelitian ini adalah pendekatan kuantitatif yang berbentuk asosiatif karena penelitian ini bertujuan untuk mengetahui hubungan antara dua variabel atau lebih, yaitu pengaruh kepuasan kerja, komitmen organisasional, motivasi kerja dan OCB di LPD Desa Pakraman Tanjung Benoa. Lokasi penelitian dilakukan di LPD Desa Pakraman Tanjung Benoa yang berlokasi di Jl. Segara Ening. No 17A. Tanjung Benoa Bali.Lokasi ini dipilih karena ditemukan masalah-masalah yang terkait dengan OCB.

Variabel bebas dalam penelitian ini adalah kepuasan kerja $\left(\mathrm{X}_{1}\right)$, komitmen organisasional $\left(\mathrm{X}_{2}\right)$ dan motivasi kerja $\left(\mathrm{X}_{3}\right)$. Kepuasan kerja karyawan adalah tentang perasaan senang sampai tidak senang yang dirasakan karyawan terhadap berbagai aspek pekerjaannya. Puspitawati dan Riana (2014) indikator yang digunakan untuk mengukur kepuasan kerja sebagai berikut 1) Beban kerja, 2) Gaji, 3) Kenaikan jabatan, 4) Pengawasan, dan 5) Rekan kerja

Komitmen organisasional merupakan orientasi hubungan aktif antara individu dan organisasinya. Adapun indikatornya menurut Zulpikar dan Daniel (2011) terdiri dari 1) Komitmen afektif (affective commitment), 2) Komitmen berkelanjutan (continuance commitment), dan 3) Komitmen normatif (normative commitment).

Motivasi adalah kekuatan yang mendorong seseorang untuk melakukan suatu tindakan atau tidak pada hakekatnya ada secara internal dan eksternal yang dapat positif atau negatif untuk mengarahkan sangat bergantung kepada 
I Putu Adi Kusuma Putra, Pengaruh Kepuasan Kerja, Komitmen Organisasional...

ketangguhan sang pemimpin Ardana dkk. (2012:193). Adapun indikator-indikator dari motivasi adalah sebagai berikut 1) Hubungan kerja, 2) Kerjasama, 3) Prakarsa, 4) Keamanan, dan 5) Promosi.

Variabel terikat dalam penelitian ini adalah OCB (Y). OCB adalah bentuk perilaku atau kontribusi karyawan yang bukan merupakan kewajiban kerja formalnya. Adapun indikator yang digunakan adalah sebagai berikut (Organet al., 2006): 1) Altruism (sikap membantu), 2) Conscientiousness (sikap berhati-hati), 3) Sportmanship (sikap sportif), 4) Courtessy (sikap sopan) dan 5) Civic Virtue (sikap kebijakan).

Sumber data pada penelitian ini adalah sumber data primer dan sekunder Sumber primer adalah data yang diperoleh secara langsung dari responden penelitian, seperti data yang didapatkan berupa jawaban responden melalui kuisioner dan wawancara. Sumber sekunder adalah data yang diperoleh dalam bentuk sudah jadi, dikumpulkan dan diolah oleh perusahaan, seperti sejarah singkat perusahaan, data tentang jumlah pegawai serta dokumen-dokumen lain yang berkaitan dengan penulisan proposal penelitian ini.

Populasi dalam penelitian ini adalah seluruh karyawan di LPD Desa Pakraman Tanjung Benoa yang berjumlah 32 orang. Metode penentuan sampel yang digunakan adalah metode sampel jenuh, yaitu sebanyak 32 orang dari jumlah populasi yang berjumlah 32 orang dengan mengikut sertakan pemimpin.

Pengumpulan data dalam penelitian ini dilakukan dengan menggunakan metode kuisioner dan wawancara. Kuesioner merupakan metode pengumpulan data dengan menggunakan daftar pertanyaan yang disebarkan kepada karyawan 
untuk dimintai keterangan terhadap semua yang dialami dan berhubungan dengan masalah yang dibahas dalam penelitian ini. Wawancara merupakan metode pengumpulan data yang dilakukan dengan tanya jawab langsung dengan beberapa karyawan untuk memperoleh keterangan mengenai masalah yang akan diteliti.

Teknik analisis data yang digunakan dalam penelitian ini adalah analisis regresi linear berganda dalam pengolahan data, di mana teknik ini digunakan untuk mengestimasi nilai variabel dependen dengan menggunakan lebih dari satu variabel independen. Pengujian analisis linier berganda dilakukan dengan bantuan program SPSS 15.0. Model regresi linear berganda sebagai berikut (Wirawan, 2014:254):

$$
Y=a+b_{1} X_{1}+b_{2} X_{2}+b_{3} X_{3}+\mu
$$

Keterangan:

$$
\begin{aligned}
& \mathrm{Y}=\text { Organizational Citizenship Behavior } \\
& \mathrm{X}_{1} \quad=\text { Kepuasan Kerja } \\
& \mathrm{X}_{2}=\text { Komitmen Organisasi } \\
& \mathrm{X}_{3}=\text { Motivasi Kerja } \\
& \mu \quad=\text { Variabel pengganggu yang berpengaruh terhadap } \mathrm{Y} \text { tetapi tidak } \\
& \text { a = bilangan Konstanta } \\
& b_{1}-b_{2}-b_{3}=\text { koefisien regresi variabel } X_{1}-X_{2}-X_{3}
\end{aligned}
$$

\section{HASIL DAN PEMBAHASAN}

Uji validitas digunakan untuk mengetahui valid tidaknya kuesioner dalam pengumpulan data. Tabel 1 menujukkan seluruh item pertanyaan menunjukkan nilai $r_{\text {hitung }}>r_{\text {tabel }}$ pada nilai signifikansi 5 persen, sehingga seluruh indikator variabel dalam penelitian ini adalah valid, sehingga dapat digunakan sebagai instrumen penelitian. 
Tabel 1

Hasil Uji Validitas Variabel Penelitian

\begin{tabular}{|c|c|c|c|c|}
\hline Variabel & Indikator & $\mathbf{r}_{\text {hitung }}$ & $\mathbf{r}_{\text {tabel }}$ & Keterangan \\
\hline \multirow{5}{*}{ Kepuasan Kerja $\left(\mathrm{X}_{1}\right)$} & $\mathrm{X}_{1.1}$ & 0,795 & 0,361 & Valid \\
\hline & $\mathrm{X}_{1.2}$ & 0,677 & 0,361 & Valid \\
\hline & $X_{1.3}$ & 0,609 & 0,361 & Valid \\
\hline & $\mathrm{X}_{1.4}$ & 0,735 & 0,361 & Valid \\
\hline & $\mathrm{X}_{1.5}$ & 0,825 & 0,361 & Valid \\
\hline \multirow{3}{*}{$\begin{array}{l}\text { Komitmen } \\
\text { Organisasional }\left(\mathrm{X}_{2}\right)\end{array}$} & $\mathrm{X}_{2.1}$ & 0,880 & 0,361 & Valid \\
\hline & $\mathrm{X}_{2.2}$ & 0,891 & 0,361 & Valid \\
\hline & $\mathrm{X}_{2.3}$ & 0,808 & 0,361 & Valid \\
\hline \multirow{5}{*}{ Motivasi Kerja $\left(\mathrm{X}_{3}\right)$} & $X_{3.1}$ & 0,630 & 0,361 & Valid \\
\hline & $X_{3.2}$ & 0,814 & 0,361 & Valid \\
\hline & $\mathrm{X}_{3.3}$ & 0,776 & 0,361 & Valid \\
\hline & $\mathrm{X}_{3.4}$ & 0,785 & 0,361 & Valid \\
\hline & $\mathrm{X}_{3.5}$ & 0,750 & 0,361 & Valid \\
\hline \multirow{5}{*}{$\begin{array}{l}\text { Organizational } \\
\text { Citizenship Behaviour } \\
\text { (Y) }\end{array}$} & $\mathrm{Y}_{1}$ & 0,781 & 0,361 & Valid \\
\hline & $\mathrm{Y}_{2}$ & 0,859 & 0,361 & Valid \\
\hline & $\mathrm{Y}_{3}$ & 0,730 & 0,361 & Valid \\
\hline & $\mathrm{Y}_{4}$ & 0,427 & 0,361 & Valid \\
\hline & $Y_{5}$ & 0,743 & 0,361 & Valid \\
\hline
\end{tabular}

Sumber: Data diolah, 2017

Suatu variabel dapat dikatakan reliabel jika memberikan nilai Cronbach

Alphalebih besar atau diatas dari 0,70 (Ghozali, 2009:45). Pengujian reliabilitas dalam penelitian ini memperoleh hasil yang diramgkum pada Tabel 2 berikut.

Tabel 2

Hasil Uji Reliabilitas Variabel Penelitian

\begin{tabular}{llrr}
\hline No. & \multicolumn{1}{c}{ Variabel } & $\begin{array}{c}\text { Cronbach's } \\
\text { Alpha }\end{array}$ & Keterangan \\
\hline $\mathbf{1}$ & Kepuasan Kerja $\left(\mathrm{X}_{1}\right)$ & 0,787 & Reliabel \\
$\mathbf{2}$ & Komitmen Organisasional $\left(\mathrm{X}_{2}\right)$ & 0,848 & Reliabel \\
$\mathbf{3}$ & Motivasi Kerja $\left(\mathrm{X}_{3}\right)$ & 0,794 & Reliabel \\
$\mathbf{4}$ & Organizational Citizenship Behaviour $(\mathrm{Y})$ & 0,784 & Reliabel \\
\hline \multicolumn{2}{l}{ Sumber: Data diolah, 2017}
\end{tabular}

Hasil uji reliabilitas yang disajikan dalam Tabel 2 menunjukkan bahwa seluruh instrumen penelitian yaitu kepuasan kerja, komitmen organisasional, motivasi kerja,dan organizational citizenship behavior memiliki koefisien Cronbach's Alpha lebih dari 0,70. Maka dapat disimpulkan bahwa seluruh indikator variabel dalam penelitian ini adalah reliabel, sehingga dapat digunakan sebagai instrumen penelitian. 
Pengujian berikutnya sebelum analisis regresi linear berganda adalah uji asumsi klasik. Uji ini dilakukan dengan tujuan untuk memastikan hasil yang diperoleh memenuhi asumsi dasar di dalam analisis regresi. Hasil uji asumsi klasik yang dilakukan dalam penelitian ini adalah uji normalitas, uji multikoliniearitas, dan uji heteroskedastisitas.

Uji ini bertujuan untuk mengetahui apakah residual dari model regresi yang dibuat berdistribusi normal atau tidak. Untuk menguji apakah data yang digunakan normal atau tidak dapat dilakukan dengan menggunakan uji Kolmogorov Sminarnov. Apabila koefisien Asymp. Sig. (2-tailed) lebih besar dari 0,05 maka data tersebut dikatakan berdistribusi normal. Berdasarkan Tabel 3 dapat dilihat bahwa nilai Kolmogorov Sminarnov (K-S) sebesar 0,625, sedangkan nilai Asymp. Sig. (2-tailed) sebesar 0,829. Hasil tersebut mengindikasikan bahwa model persamaan regresi tersebut berdistribusi normal karena nilai Asymp. Sig. (2tailed) 0,829lebih besar dari nilai alpha 0,05 .

\section{Tabel 3}

Hasil Uji Normalitas

\begin{tabular}{lr}
\hline & Unstandardized Residual \\
\hline $\mathrm{N}$ & 32 \\
Kolmogorov-Smirnov Z & 0,625 \\
Asymp.Sig.(2-tailed) & 0,829 \\
\hline Sumber: Data diolah, 2017 &
\end{tabular}

Uji ini bertujuan untuk menguji apakah pada model regresi ditemukan adanya korelasi antar variabel bebas. Adanya multikolinearitas dapat dilihat dari nilai tolerance atau variance inflation factor (VIF). Jika nilai tolerance lebih dari $10 \%$ atau VIFKurang dari 10, maka dikatakan tidak ada multikolinearitas. Berdasarkan Tabel 4 dapat dilihat bahwa nilai tolerance dan VIF dari seluruh variable menunjukkan bahwa nilai tolerance untuk setiap variabel lebih besar dari 
I Putu Adi Kusuma Putra, Pengaruh Kepuasan Kerja, Komitmen Organisasional...

10\% dan nilai VIF lebih kecil dari 10 yang berarti model persamaan regresibebas dari multikolinearitas.

Tabel 4

Hasil Uji Multikoleniaritas

\begin{tabular}{lrc}
\hline \multicolumn{1}{c}{ Variabel } & Tolerance & VIF \\
\hline Kepuasan Kerja $\left(\mathrm{X}_{1}\right)$ & 0,593 & 1,685 \\
Komitmen Organisasional $\left(\mathrm{X}_{2}\right)$ & 0,974 & 1,026 \\
Motivasi Kerja $\left(\mathrm{X}_{3}\right)$ & 0,600 & 1,665 \\
\hline
\end{tabular}

Sumber: Data diolah, 2017

Uji ini bertujuan untuk mengetahui apakah dalam model regresi terjadi ketidaksamaan varians dari residual satu pengamatan ke pengamatan lain yang dilakukan dengan uji Glejser. Jika tidak ada satu pun variabel bebas yang berpengaruh signifikan terhadap nilai absolute residual atau nilai signifikansinya di atas 0,05 maka tidak mengandung gejala heteroskedastisitas.

Tabel 5

Hasil Uji Heteroskedastisitas

\begin{tabular}{|c|c|c|c|c|c|c|}
\hline \multirow{2}{*}{\multicolumn{2}{|c|}{ Model }} & \multicolumn{2}{|c|}{$\begin{array}{l}\text { Unstandardized } \\
\text { Coefficients }\end{array}$} & \multirow{2}{*}{$\begin{array}{c}\text { Standardized } \\
\text { Coefficients } \\
\text { Beta }\end{array}$} & \multirow[t]{2}{*}{$\mathbf{t}$} & \multirow[t]{2}{*}{ Sig. } \\
\hline & & B & Std. Error & & & \\
\hline 1 & (Constant) & .373 & .048 & & 7.756 & .000 \\
\hline & Kepuasan Kerja & .035 & .063 & .131 & .549 & .587 \\
\hline & Komitmen Organisasional & -.053 & .050 & -.198 & -1.064 & .297 \\
\hline & Motivasi Kerja & -.030 & .063 & -.114 & -.481 & .634 \\
\hline
\end{tabular}

Pada Tabel 5 dapat dilihat bahwa nilai Sig. dari variabel kepuasan kerja, komitmen organisasional, dan motivasi kerja,masing-masing sebesar 0,587, 0,297, dan 0,634 . Nilai tersebut lebih besar dari 0,05 yang berarti tidak terdapat pengaruh antara variabel bebas terhadap absolute residual. Dengan demikian, model yang dibuat bebas gejala heteroskedastisitas.

Pengujian data dalam penelitian ini menggunakan teknik analisis regresi linier berganda. Analisis regresi linear berganda digunakan untuk mengetahui atau memperoleh gambaran mengenai pengaruh kepuasan kerja $\left(\mathrm{X}_{1}\right)$, Komitmen 
organisasional $\left(\mathrm{X}_{2}\right)$, dan motivasi kerja $\left(\mathrm{X}_{3}\right)$, pada organizational citizenship behaviour (Y). Perhitungan koefisien regresi linier berganda dilakukan dengan analisis regresi melalui software SPSS 18.0for Windows, diperoleh hasil yang ditunjukan pada Tabel 6 .

Tabel 6

Hasil Analisis Regresi Linier Berganda

\begin{tabular}{lrrr}
\hline \multicolumn{1}{c}{ Variabel } & $\begin{array}{c}\text { Nilai Koefisien } \\
\text { Regresi }\end{array}$ & t hitung & \multicolumn{1}{c}{$\begin{array}{c}\text { Nilai } \\
\text { Signifikansi }\end{array}$} \\
\hline Kepuasan Kerja $\left(\mathrm{X}_{1}\right)$ & 0,543 & 4,776 & 0,000 \\
Komitmen Organisasional $\left(\mathrm{X}_{2}\right)$ & 0,238 & 2,676 & 0,012 \\
Motivasi Kerja $\left(\mathrm{X}_{3}\right)$ & 0,418 & 3,696 & 0,001 \\
\hline R Square & & & $\mathbf{0 , 7 8 5}$ \\
Adjusted R Square & & & $\mathbf{0 , 7 6 2}$ \\
F Statistik & & & $\mathbf{3 4 , 1 1 3}$ \\
Signifikansi & & $\mathbf{0 , 0 0 0}$ \\
\hline Sumber: Data diolah, 2017 & & &
\end{tabular}

Berdasarkan hasil analisis regresi linier berganda seperti yang disajikan pada Tabel 6, maka dapat dibuat persamaan strukturalnya sebagai berikut.

$$
\mathrm{Y}=0,543 \mathrm{X} 1+0,238 \mathrm{X} 2+0,418 \mathrm{X} 3
$$

Koefisien determinasi $\left(\mathrm{R}^{2}\right)$ digunakan untuk mengukur seberapa jauh kemampuan model dalam menerangkan variasi variabel dependen (Ghozali, 2009:97). Nilai koefisien determinasi yaitu nilai antara 0 (nol) sampai 1 (satu). Nilai koefisien determinasi yang kecil dapat diartikan kemampuan variabelvariabel independen dalam menjelaskan variasi variabel dependen sangat terbatas. Sebaliknya nilai koefisien determinasi yang tinggi atau mendekati satu dapat diartikan bahwa variabel independen memberikan hampir semua informasi yang dibutuhkan untuk meprediksi variasi variabel dependen. Hasil koefisien determinasi pada Tabel 6 menunjukkan nilai determinasi total sebesar 0,762 mempunyai arti bahwa sebesar 76,2 persen variasi organizational citizenship 
I Putu Adi Kusuma Putra, Pengaruh Kepuasan Kerja, Komitmen Organisasional...

behaviourdipengaruhi oleh variasi kepuasan kerja, komitmen organisasional, dan motivasi kerja,sedangkan sisanya sebesar 23,8 persen dijelaskan oleh faktor lain yang tidak dimasukkan ke dalam model.

Pengujin berikutnya uji Anova untuk mengetahui kelayakan pengaruh kepuasan kerja, komitmen organisasional, dan motivasi kerja, pada OCB karyawan LPD Desa Pakraman Tanjung Benoa. Hubungan antara variabel bebas dapat dikatakan signifikan mempengaruhi OCB karyawan LPD Desa Pakraman Tanjung Benoa apabila hasil dari uji $\mathrm{F}$ signifikan atau $\mathrm{P}$ value $<0,05$ sehingga model regresi yang digunakan tersebut dianggap layak uji. Hasil uji kelayakan model dalam penelitian ini dipaparkan dalam Tabel 7.

Tabel 7

Hasil Uji Anova

\begin{tabular}{llrrrrr}
\hline Model & & Sum of Squares & df & Mean Square & F & Sig. \\
\hline 1 & Regression & 24.340 & 3 & 8.113 & 34.113 & $.000^{\mathrm{a}}$ \\
& Residual & 6.660 & 28 & .238 & & \\
& Total & 31.000 & 31 & & & \\
\hline
\end{tabular}

Sumber: Data diolah, 2017

Hasil uji anova (UJI F) pada Tabel 7, menunjukkan nilai antar kelompok pembanding $(\mathrm{df}$ regression $=3$ ), nilaidalam kelompok penyebut $(\mathrm{df}$ residual $=28$ ), pada alfa sebesar 0,05 maka nilai $F$ tabelnya adalah $\mathrm{F} 0,05(5,150)=2,95$. Sedang $\mathrm{F}$ hitung $=34,113$. Nilai Fhitung lebih besar dari Ftabel yakni 34,113 >2,95, dengan nilai signifikansi $0,000<0,05$, maka H0 ditolak. Kesimpulannya, pada kelompok yang diuji memiliki perbedaan yang nyata (signifikan) berarti bahwa kepuasan kerja, komitmen organisasional, dan motivasi kerja secara simultan berpengaruh signifikan terhadap OCB.

Pengujian berikutnya adalah analisis pengaruh kepuasan kerja terhadap OCB diperoleh nilai signifikansi sebesar 0,000 dengan nilai koefisien regresi 
0,543. Nilai Signifikansi $0,000<0,05$ mengindikasikan bahwa $\mathrm{H}_{0}$ ditolak dan $\mathrm{H}_{1}$ diterima. Hasil ini mempunyai arti bahwa kepuasan kerja berpengaruh positif dan signifikan terhadap OCB di LPD Desa Pakraman Tanjung Benoa.

Kepuasan kerja karyawan adalah tentang perasaan senang sampai tidak senang yang dirasakan karyawan terhadap berbagai aspek pekerjaannya. Jika seorang karyawan mendapatkan kepuasan kerja yang tinggi maka karyawan tersebut akan menunjukkan produktivitas kerja yang baik, sebaliknya karyawan yang mendapatkan kepuasan kerja yang rendah maka karyawan tersebut akan menunjukkan produktivitas yang tidak baik pada perusahaan.Hasil pengujian penelitian ini menunjukan bahwa kepuasan kerjamemiliki pengaruh yang positif dan signifikan terhadap OCB. Artinya, semakin tinggi kepuasan kerja yang dirasakan karyawan, maka OCB karyawan juga akan meningkat. Hasil penelitian ini diperkuat oleh Krishnan et al. (2009) yang menunjukkan bahwa baik kepuasan kerja intrinsik maupun kepuasan kerja ekstrinsik berpengaruh signifikan terhadap OCB. Penelitian serupa yang dilakukan oleh Triwibowo dan Arsanti (2016), Ngadiman et al. (2013), Darmawati dan Indartono (2015), , Dewi dan Suwandana (2016), dan Osman et al. (2015) juga menemukan bahwa kepuasan kerja berpengaruh positif signifikan terhadap OCB.

Berdasarkan hasil analisis pengaruh komitmen organisasional terhadap organizational citizenship behaviour diperoleh nilai signifikansi sebesar 0,012 dengan nilai koefisien regresi 0,238. Nilai Signifikansi $0,012<0,05$ mengindikasikan bahwa $\mathrm{H}_{0}$ ditolak dan $\mathrm{H}_{2}$ diterima. Hasil ini mempunyai arti 
I Putu Adi Kusuma Putra, Pengaruh Kepuasan Kerja, Komitmen Organisasional...

bahwa komitmen organisasional berpengaruh positif dan signifikan terhadap Organizational Citizenship Behavior di LPD Desa Pakraman Tanjung Benoa.

Komitmen organisasional adalah suatu pengakuan seutuhnya sebagai suatu sikap diri dalam diri karyawan didalam organisasi dan keinginan untuk tetap tinggal di organisasi tersebut serta setia kepada organisasinya, mengerahkan usaha ekstra untuk pencapaian tujuan dan pengidentifikasi karyawan dalam memenuhi tujuan organisasi (Obalola et al., 2012). Hasil pengujian penelitian ini menunjukan bahwa komitmen organisasionalmemiliki pengaruh yang positif dan signifikan terhadap OCB. Artinya, semakin tinggi komitmen organisasional karyawan LPD Desa Pakraman Tanjung Benoa, maka semakin tinggi OCB yang dilakukan karyawan. Hasil penelitian ini didukung dengan penelitian yang dilakukan olehMerry (2013) yang menyatakan bahwa komitmen organisasional mempunyai pengaruh positif dan signifikan terhadap OCB. Zeinabadi (2010) juga menemukan bahwa komitmen organisasional mempunyai pengaruh yang signifikan terhadap OCB. Penelitian serupa yang dilakukan oleh Darmawati et al. (2013), Prameswari dan Suwandana (2017),Fitria dkk. (2015), dan Kurniawan (2015) juga menunjukkan hasil bahwa komitmen organisasional memiliki hubungan yang positif dan signifikan terhadap OCB.

Berdasarkan hasil analisis pengaruh motivasi kerja terhadap organizational citizenship behaviour diperoleh nilai signifikansi sebesar 0,001 dengan nilai koefisien regresi 0,418 . Nilai Signifikansi $0,001<0,05$ mengindikasikan bahwa $\mathrm{H}_{0}$ ditolak dan $\mathrm{H}_{3}$ diterima. Hasil ini mempunyai arti 
bahwa motivasi kerja berpengaruh positifdan signifikan terhadap Organizational Citizenship Behavior di LPD Desa Pakraman Tanjung Benoa.

Motivasi adalah suatu keinginan atau kehendak yang timbul dari dalam diri karyawan yang dapat mendorong munculnya semangat untuk bekerja secara maksimal agar perusahaan dapat mencapai tujuannya. Hasibuan (2007) menyebutkan bahwa motivasi merupakan suatu cara bagaimana mendorong gairah kerja bawahan agar mereka mau bekerja keras dengan memberikan semua kemampuan dan keterampilannya untuk menwujudkan tujuan perusahaan. Penerapan motivasi yang tepat dapat mendorong mereka melaksanakan tugasnya semaksimal mungkin, sehingga akan meningkatkan kinerja karyawan yang bersangkutan.Hasil pengujian penelitian ini menunjukan bahwa motivasi kerjamemiliki pengaruh yang positif dan signifikan terhadap OCB. Artinya, semakin baik motivasi kerja yang diperoleh karyawan LPD Desa Pakraman Tanjung Benoa, maka OCB karyawan juga akan semakin meningkat. Hasil penelitian ini didukung dengan penelitian yang dilakukan oleh Djati (2011) yang memperoleh hasil bahwa motivasi kerja berpengaruh terhadap OCB. Penelitian serupa oleh Kusuma (2014), Budiyanto dan Oetomo (2011), Simon dan Naftalia (2016), Dewi (2015), serta Suhardi dan Syaifullah (2017)juga menemukan hasil bahwa, motivasi kerja berpengaruh positif dan signifikan terhadap OCB.

\section{KETERBATASAN PENELITIAN}

Berdasarkan penelitian yang telah dilakukan, terdapat keterbatasan dalam penelitian ini yaitu ruang lingkup penelitian hanya mencakup LPD Desa Pakraman Tanjung Benoa yang merupakan salah satu LPD yang berada di 
I Putu Adi Kusuma Putra, Pengaruh Kepuasan Kerja, Komitmen Organisasional...

Provinsi Bali sehingga tidak dapat menggambarkan seluruh LPD lainnya secara umum di Bali. Data penelitian dikumpulkan dari 32 orang karyawan LPD Desa Pakraman Tanjung Benoa. Jumlah data yang terbatas menyebabkan generalisasi data terbatas, maka perlu dilakukan pengambilan data di luar lingkungan LPD Desa Pakraman Tanjung Benoa.

Faktor yang mempengaruhi OCB dalam penelitian ini adalah kepuasan kerja, komitmen organisasional dan motivasi kerja, sedangkan masih banyak faktor lain yang mempengaruhi OCB karyawan seperti komunikasi organisasi, lingkungan kerja, gaya kepemimpinan dan faktor-faktor lainnya. Penelitian ini hanya dilakukan dalam titik waktu tertentu (cross section), sedangkan lingkungan setiap saat berubah (dinamis), sehingga penelitian ini penting untuk dilakukan kembali.

\section{SIMPULAN DAN SARAN}

Hasil penelitian menujukkan bahwa Kepuasan kerja berpengaruh positif dan signifikan terhadap OCB. Artinya, kepuasan kerja yang tinggi akan meningkatkan OCB karyawan. Komitmen organisasional karyawan berpengaruh positif dan signifikan terhadap OCB. Artinya, semakin tinggi komitmen organisasi yang dimiliki karyawan maka semakin tinggi perilaku OCB karyawan. Motivasi kerja berpengaruh positif dan signifikan terhadap OCB. Artinya, semakin besar motivasi kerja yang dimiliki oleh karyawan maka semakin tinggi intensitas OCB karyawan. 
Saran yang dapat diberikan dari hasil penelitian adalah untuk meningkatkan kepuasan kerja karyawan, maka pimpinan LPD Desa Pakraman Tanjung Benoa sebaiknya lebih memperhatikan karyawan yang kurang bekerja dengan penuh tanggung jawab dengan cara menciptakan kegiatan teamwork (kerja tim) yang menyenangkan secara rutin dengan leader teamwork (kerja tim) yang selalu bergantian agar hubungan antar rekan kerja dapat terbina dengan baik yang dapat meningkatkan kepuasan kerja karyawan tersebut. Pimpinan LPD Desa Pakraman Tanjung Benoa sebaiknya tidak membeda-bedakan dan menilai negatif prakarsa yang disampaikan oleh bawahan, pemimpin disarankan dapat menciptakan hubungan tenaga kerja yang positif baik antara atasan dengan karyawan maupun antara sesama karyawan, agar karyawan merasa nyaman dengan lingkungan kerja dan dapat meningkatkan motivasi karyawan dalam bekerja. Agar komitmen oganisasional dapat terwujud dan OCB dapat ditingkatkan, sebaiknya pimpinan perusahaan membuat sosialisasi seperti seminar ataupun training (latihan) kepada karyawan mengenai pentingnya komitmen terhadap organisasi dan lebih tegas dalam memberikan sanksi kepada karyawan yang tidak mematuhi peraturan perusahaan, agar seluruh karyawan menjadi lebih disiplin dan dapat memahami pentingnya komitmen terhadap organisasinya.

\section{REFERENSI}

Achmad Sani. 2013. Role of Procedural Justice, Organizational Commitment and Job Satisfaction on Job Performance: The Mediating Effects of Organizational Citizenship Behavior. International Journal of Business and Management; 8(15).

Ardana, Komang. Ni Wayan Mujiati dan I Wayan Mdiartha Utama, 2012. Manajemen Sumber Daya Manusia. Edisi I. Yogyakarta: Graha Ilmu. 
I Putu Adi Kusuma Putra, Pengaruh Kepuasan Kerja, Komitmen Organisasional...

Aydogdu, Sinem dan Asikgil, Baris. 2011. An Empirical Study of the Relationship Among Job Satisfaction, Organizational Commitment and Turnover Intention. International Review of Management and Marketing, 1(3), pp: 43-53.

Bangkit, Torang Arise. 2010. Hubungan Antara Komitmen Organisasi dan Intensi Tunover dengan Organizational Citizenship Behavior pada Karyawan PT Lotte Shopping Indonesia. Skripsi.Fakultas Kedokteran Universitas Sebelas Maret Surakarta.

Budiyono dan Oetomo. 2011. The effect Of Job Motivation, Work Environment and Leadership on Organizational Citizenship Behavior, Job Satisfaction and Public Service Quality in Magetan, East Java, Indonesia. World Academy of Science, Engineering and Technology 75, 2011.

Bakotic, Danica, and Babic, Tomislav. 2013. Relationship between Working Conditions and Job Satisfaction: The Case of Croation Shipbuilding Company. International Journal of Business and Social Sciense, 4(2).

Darmawati, Arum., Hidayati, Lina Nur., Herlina S., Dina. (2013). Pengaruh Kepuasan Kerja dan Komitmen Organisasi terhadap Organizational Citizenship Behavior - Jurnal Economia, 9(1), 10-17.

Darmawati, Arum., dan Indartono, Setyabudi. 2015. Pengaruh Kepuasan Kerja Terhadap Organizational Citizenship Behavior Dengan Komitmen Organisasi Sebagai Variabel Mediasi. Jurnal Ilmu Manajemen, 12(2), h:: 49-64

Dewi, Ni Luh Putu Yanti Astika., dan Suwandana, I Gusti Made. 2016. Pengaruh Kepuasan Kerja Terhadap Organizational Citizenship Behavior (OCB) Dengan Komitmen Organisasional Sebagai Variabel Mediasi. E-Jurnal Manajemen Unud, 5(9), h: 5643-5670

Djati, S. P. \& Wahyu A. R. 2011. Penerapan Organizational Citizenship Behavior dalam manajemen sumber daya manusia pada perguruan tinggi. Jurnal Mitra Ekonomi dan Manajemen Bisnis. 2 (2), h: 259-272.

Fitria, Rilma Maulida., Dewi, Roswita Santia, dan Febriana, Silvia Kristanti Tri. 2015. Peranan Komitmen Organisasi Terhadap Organizational Citizenship Behavior Pada Perawat.Jurnal Ecopsy, 2(1), h: 8-12.

Gomes, D. R., Asseiro, V., \& Ribeiro, N. 2013.Triggering Employee Motivation in Adverse Organizational Contexts: "Going the Extra Mile" while Holding Hands with Uncertainty? Business and Management Research, 2(1), pp: 41-54.

Handoko, T. Hani. 2009. Manajemen. Edisi Kedua. Yogyakarta : BPFE. 
Hariandja, Marihot Tua Effendi. 2009. Manajemen Sumber Daya Manusia. Cetakan ke 5. Jakarta: PT. Grasindo.

Hariyanti, Primawestri. 2010. Pengaruh Komunikasi dan Motivasi Kerja Terhadap Kinerja Perawat dengan Komitmen Organisasi Sebagai Variabel Moderating. Jurnal Ekonomi dan Bisnis, 20(22), h: 1-15.

Hasibuan, Malayu. 2008. Manajemen Sumber Daya Manusia. Edisi Revisi. Jakarta: Bumi Aksara.

Huang, C, C., You, C. S., and Tsai, M. T., 2012. A Multidimensional Analysis of Ethical Climate, Job Statisfaction, Organizational Commitment, and Organizational Citizenship Behavior, Nursing Ethics, 19(4), pp: 513529.

Krishnan R., Arumugam, N., Chandran, V., and Kanchymalay, K. 2009. Examining the Relationship between Job Satisfaction and Organizational Citizenship Behavior: A Case Study among Non Academic Staffs in A Public Higher Learning Institution in Malaysia, Global Business Summit Conference, 2(3), pp: 221-232.

Kurniawan, Albert. 2015. Pengaruh Komitmen Organisasi Terhadap Organizational Citizenship Behavior (OCB) PT X Bandung. Jurnal Manajemen, 15(1), h: 95-118.

Kusuma, Lingga Sakti. 2014. Pengaruh Motivasi Kerja Dan Kepuasan Kerja Terhadap Organizational Citizenship Behavior Pegawai RRI Yogyakarta. Skripsi. Fakultas Ekonomi Universitas Negeri Yogyakarta.

Merry Ristiana, M. 2013. Pengaruh Komitmen Organisasi Dan Kepuasan kerja Terhadap Organizational Citizenship Behavior (Organizational Citizenship Behavior) Dan Kinerja Karyawan Rumah Sakit Bhayangkara Trijata Denpasar.Jurnal Ilmu Ekonomi \& Manajemen, 9(1), h: 56-70.

Ngadiman., Anis Eliyana, and Dwi Ratmawati. 2013. Influence of Transformational Leadership and Organizational Climate to the Work Satisfaction, Organizational Commitment and Organizational Citizenship Behavior on the Education Personnel of Sebelas Maret University, Surakarta. European Journal of Business and Management, 5(10), pp: 97114.

Osman , A., Yusuf Haji Othman, S M Sohel Rana, Mohhamad Solaiman \& Bharat Lal. 2015. The Influence of Job Satisfaction, Job Motivation \& Percieved Organizational Support toward Organizational Citizenship Behavior (Organizational Citizenship Behavior) in Malaysia. Asian Social Science; 11(21), pp: 174-182.

Perdana, Adam M. P. 2010. Pengaruh Persepsi Gaya Kepemimpinan dan Kepuasan Kerja terhadap Organizational Citizenship Behaviorpada 
I Putu Adi Kusuma Putra, Pengaruh Kepuasan Kerja, Komitmen Organisasional...

Karyawan PT Bumi Serpong Damai Tbk. Tanggerang. Skripsi Sarjana Jurusan Psikologis pada Fakultas Psikologi Universitas Islam Negeri, Syarif Hidayatullah, Jakarta.

Prameswari, Ni Kadek Setya., dan Suwandana, I Gusti Made. 2017. Pengaruh Keadilan Organisasional, Komitmen Organisasional, dan Kepuasan Kerja Terhadap Organizational Citizenship Behavior. E-Jurnal Manajemen Unud, 6(3), h: 1368-1397

Puspitawati, N.M.D., \& Riana, I. G., (2014). Pengaruh Kepuasan Kerja Terhadap Komitmen Organisasional dan Kualitas layanan. Jurnal Manajemen Strategi Bisnis dan kewirausahaan. Fakultas Ekonomi Dan Bisnis Universitas Udayana 8 (1).

Rivai, Veithzal, dan sagala, jauvani. 2008. Manajemen Sumber Daya Manusia. Jakarta: Rajawali pers.

Robbins, S.P., and Judge, T.A. 2008. Perilaku Organisasi, Edisi Kedua belas,Jakarta: Salemba Empat.

Simon, Angelia., dan Naftalia G, Stevanie. 2016. Analisa Pengaruh Motivasi Kerja Terhadap Organizational Citizenship Behaviour (OCB) Melalui Kepuasan Kerja Karyawan Di Restaurant Halim Surabaya. Jurnal Hospitality dan Manajemen Jasa. 4(1), h: 347-361.

Suhardi. dan Syaifullah. 2017. Pengaruh Motivasi, Kompetensi, Lingkungan Kerja, Kompensasi Terhadap Organizational Citizenship Behavior Dan Kinerja Karyawan Asuransi Jiwa Di Provinsi Kepulauan Riau. Jurnal Benefit, 2(1), h: 55-71

Sutrisno, H. Edy. 2014. Manajemen Sumber Daya Manusia. Jakarta: Kencana Prenada Media Group.

Wagner, Sharon L \& Rush, Michael C. 2000. Altruistic Organizational Citizenship Behavior: Context, desposition, and age, The Journal of Social Psychology; Jun; 140, 3; ProQuest Medical Library pg. 379.

Widodo, Suparno Eko. 2015. Manajemen Pengembangan Sumber Daya Manusia. Yogyakarta. Pustaka Pelajar.

Winardi, J. 2008. Motivasi dan Permotivasian dalam Manajemen. Jakarta: Rajawali Pers.

Wirawan, Nata. 2014. Cara Mudah Memahami Statistik 2 (Statistik Infrensia) Untuk Ekonomi dan Bisnis. Edisi Ketiga. Denpasar: Keraras Emas.

Zeinabadi, Hassanreza (2010). Job Satisfaction and Organizational Commitment as Antecedents of Organizational Citizenship Behavior (Organizational Citizenship Behavior) of Teachers - Procedia Social and Behavioral Sciences, 5, pp: 988-1003. 